\title{
Trends of long noncoding RNA research from 2007 to 2016: a bibliometric analysis
}

\author{
Yan Miao' ${ }^{1}$, Si-Yi Xu' ${ }^{1}$, Lu-Si Chen ${ }^{2}$, Ge-Yu Liang ${ }^{1}$, Yue-Pu Pu ${ }^{1}$ and Li-Hong Yin ${ }^{1}$ \\ ${ }^{1}$ Key Laboratory of Environmental Medicine Engineering, Ministry of Education, School of Public Health, Southeast University, \\ Nanjing, Jiangsu 210009, P.R. China \\ ${ }^{2}$ Department of Epidemiology and Health Statistics, School of Public Health, Southeast University, Nanjing, Jiangsu 210009, \\ P.R. China \\ Correspondence to: Li-Hong Yin, email: Ih.yin62@gmail.com \\ Yan Miao, email: yan.miaol@outlook.com \\ Keywords: IncRNA, citation, bibliometric, CiteSpace IV, WoSCC
}

Received: August 01, $2017 \quad$ Accepted: August 18, $2017 \quad$ Published: September 12, 2017

Copyright: Miao et al. This is an open-access article distributed under the terms of the Creative Commons Attribution License 3.0 (CC BY 3.0), which permits unrestricted use, distribution, and reproduction in any medium, provided the original author and source are credited.

\section{ABSTRACT}

Purpose: This study aims to analyze the scientific output of long noncoding RNA (IncRNA) research and construct a model to evaluate publications from the past decade qualitatively and quantitatively.

Methods: Publications from 2007 to 2016 were retrieved from the Web of Science Core Collection database. Microsoft Excel 2016 and CiteSpace IV software were used to analyze publication outputs, journals, countries, institutions, authors, citation counts, ESI top papers, $\mathrm{H}$-index, and research frontiers.

Results: A total of 3,008 papers on IncRNA research were identified published by June 17, 2017. The journal, Oncotarget (IF2016, 5.168) ranked first in the number of publications. China had the largest number of publications $(1,843)$, but the United States showed its dominant position in both citation frequency $(45,120)$ and $H$-index (97). Zhang Y (72 publications) published the most papers, and Guttman M (1,556 citations) had the greatest co-citation counts. The keyword "database" ranked first in research frontiers.

Conclusion: The annual number of publications rapidly increased in the past decade. China showed its significant progress in IncRNA research, but the United States was the actual leading country in this field. Many Chinese institutions engaged in IncRNA research but significant collaborations among them were not noted. Guttman M, Mercer TR, Rinn JL, and Gupta RA were identified as good candidates for research collaboration. "Database," "Xist RNA," and "Genome-wide association study" should be closely observed in this field.

\section{INTRODUCTION}

Long noncoding RNAs (lncRNAs) belong to a large class of non-protein coding transcribed RNA molecules with a length more than 200 nucleotides [1]. The length threshold is a simple but convenient biophysical cutoff that separates lncRNAs from smaller noncoding RNA species (e.g. miRNAs, siRNAs) [2, 3]. In the past decade,
lncRNAs have attracted investigators' much attention because the cumulative evidence indicated that lncRNAs play a pivotal role in multiple biological processes based on a variety of underlying mechanisms, including epigenetic regulation [4], organ or tissue development [5], cell development and differentiation [6], protein transport [7], gene transcription [8], chromatin remodeling [9], and metabolic processes [10]. Meanwhile, increasing 
evidence suggested that dysregulations and mutations of these lncRNAs were associated with development and progression of various human diseases, such as lung cancer [11], liver cancer [12], colon cancer [13], and breast cancer [14].

The research interest on IncRNA has increased dramatically in recent years, and many academic journals have published articles on lncRNA research. Nevertheless, few attempts have been made to analyze the evolution of scientific output in this field systematically. Bibliometrics is a good choice of method to analyze the literature of a scientific domain, and assess trends in research activity over time [15].

The objects of this study are to systematically evaluate lncRNA research from 2007 to 2016, to determine the publication pattern of IncRNA research outputs, to capture the collaboration pattern between countries/ institutions/authors, and to identify research trends and frontiers in this field.

\section{RESULTS}

\section{Publication outputs and growth prediction}

A total of 3,008 articles met the search criteria (Figure 1) (Supplementary Figure 1). The distribution of annual publications was shown in different time stage (Figure 2A). The overall trend of publication increased from one publication in 2007 to 1,342 publications in 2016.

The model fitting curve of IncRNA publication growth indicated a significant correlation $\left(\mathrm{R}^{2}=0.9943\right)$ between the cumulative number of publications and publication year as shown in Figure 2B. By using cumulative publication numbers from 2007 to 2016, the number of publication was estimated to reach 1,976 in 2017.

\section{Distribution by journals}

The 3,008 articles on IncRNA research were published in 663 academic journals (Supplementary Table 1). Among the top 15 journals (Table 1), Oncotarget, which impact factor (IF) 2016 is 5.168, contributed to the most publications on IncRNA research (203 publications, 6.75\%), followed by Tumor Biology (IF2016, 3.650; 125 publications; 4.16\%), PLoS ONE (IF2016, 2.806; 118 publications; 3.92\%), and Scientific Reports (IF2016, 4.259; 97 publications; 3.23\%).

Figure 3 presented a dual-map overlay of journals. The left side was the citing journals map, and the right side was the cited journals map. The labels on the map showed the disciplines involved in journals. The lines were citation links starting from the left and point to the journals on the right. This dual-map overlay indicated that most articles were published in molecular journals, biology journals, and immunology journals, and they mainly cited journals from molecular, biology, and genetics areas.

\section{Distribution by countries and institutions}

The 3,008 articles on IncRNA research were contributed by 57 countries/territories (Supplementary Table 2). There were extensive collaborations between countries/territories (Figure 4A). In relation to the top 10 countries that contributed to lncRNA research (Table 2 ), China had the largest number of publications (1843), followed by the United States (779), Germany (108), and England (100).

More than 2,100 institutions contributed to the publications on lncRNA research (Supplementary Table 3 ). Compared with countries, the cooperation between institutions was not significant (Figure 4B). The top 10 institutions contributed to $31.85 \%$ of the total number of publications. Nanjing Medical University led the first research echelon, followed by Shanghai Jiao Tong University, Chinese Academy of Sciences, and Harbin Medical University (Table 2).

\section{Analysis of citations, H-index, and ESI top papers}

All articles related to lncRNA research had been cited 91,530 times since 2007. In top four countries (according to the number of publications), the United States had both the largest number of citations $(45,120)$ and the highest value of $\mathrm{H}$-index (97). Especially the citation counts, the United States accounted for $49.30 \%$ of the total citations. China had the largest number of ESI top papers (141). Due to the gap in the number of publications, Germany and England had no advantage in the ranking of these three items (Figure 5).

\section{Distribution by authors}

Nearly 12,000 authors contributed to the total number of publications (Supplementary Table 4). The network map (Figure 6A) outlines the cooperation between authors. Regarding the authors who had the most publications (Table 3), Zhang Y ranked the first (72 publications), followed by Wang Y (67 publications), Wang J (63 publications), and Li J (60 publications).

CiteSpace IV mined the information on authors citation and presented it as a network map (Figure $6 \mathrm{~B})$. In relation to the top 10 co-cited authors (Table 3 ) (Supplementary Figure 2), Guttman M (1556 citations), led, followed by Mercer TR (1213 citations), Rinn JL (1147 citations), and Gupta RA (932 citations).

\section{Analysis of references}

Reference analysis is one of the most significant indicators in bibliometrics. The co-citation map of 
references suggests the scientific relevance of the publications (Figure 7A). Here, the modularity Q score was higher than 0.5 (0.5096) (Supplementary Figure 3), which indicates the network was reasonably divided into loosely coupled clusters. The average silhouette score was greater than 0.5 (0.6383) (Supplementary Figure 3), which means the homogeneity of these clusters was acceptable on average. All clusters were labeled with index terms extracted from the references (Supplementary Figure 4). The largest cluster \#0 was labeled as "long noncoding RNA," followed by the second largest cluster \#1, labeled as "macroRNA underdogs," and the third largest cluster \#2, labeled as "poor prognosis." These clusters mentioned above were also presented in a timeline view (Figure 7B).

\section{Analysis of keywords}

CiteSpace IV extracted keywords that occurred in 3,008 publications. We used CiteSpace IV to detect and analyze keywords with the strongest citation bursts (Figure 8) (Supplementary Figure 5). The keywords that had the strongest citation bursts after 2010 are as follows: "dosage compensation" (2010-2012), "in vivo" (2010-
2014), "genome-wide association" (2010-2016), "xist RNA" (2012-2016), "meta-analysis" (2014-2016), and "database" (2014-2016).

\section{DISCUSSION}

\section{General data}

According to the number of publications, the publication year can be divided into two phases. The first phase (2007-2011) could be considered as the initial stage of IncRNA research. Thus, the number of publications increased slowly during this period. With increase in the intensity of research, more findings will emerge. In the second phase (2012-2016), there was a sharp growth of publications related to lncRNA research. Thus, this stage could be considered as the golden period of development for lncRNA research. Moreover, the prediction curve indicated that there might be more publications in this field in the following years. The development prospects of lncRNA research could be expected.

Regarding the top 15 journals, 2 of the journals, including Nucleic Acids Research (IF2016, 10.162) and

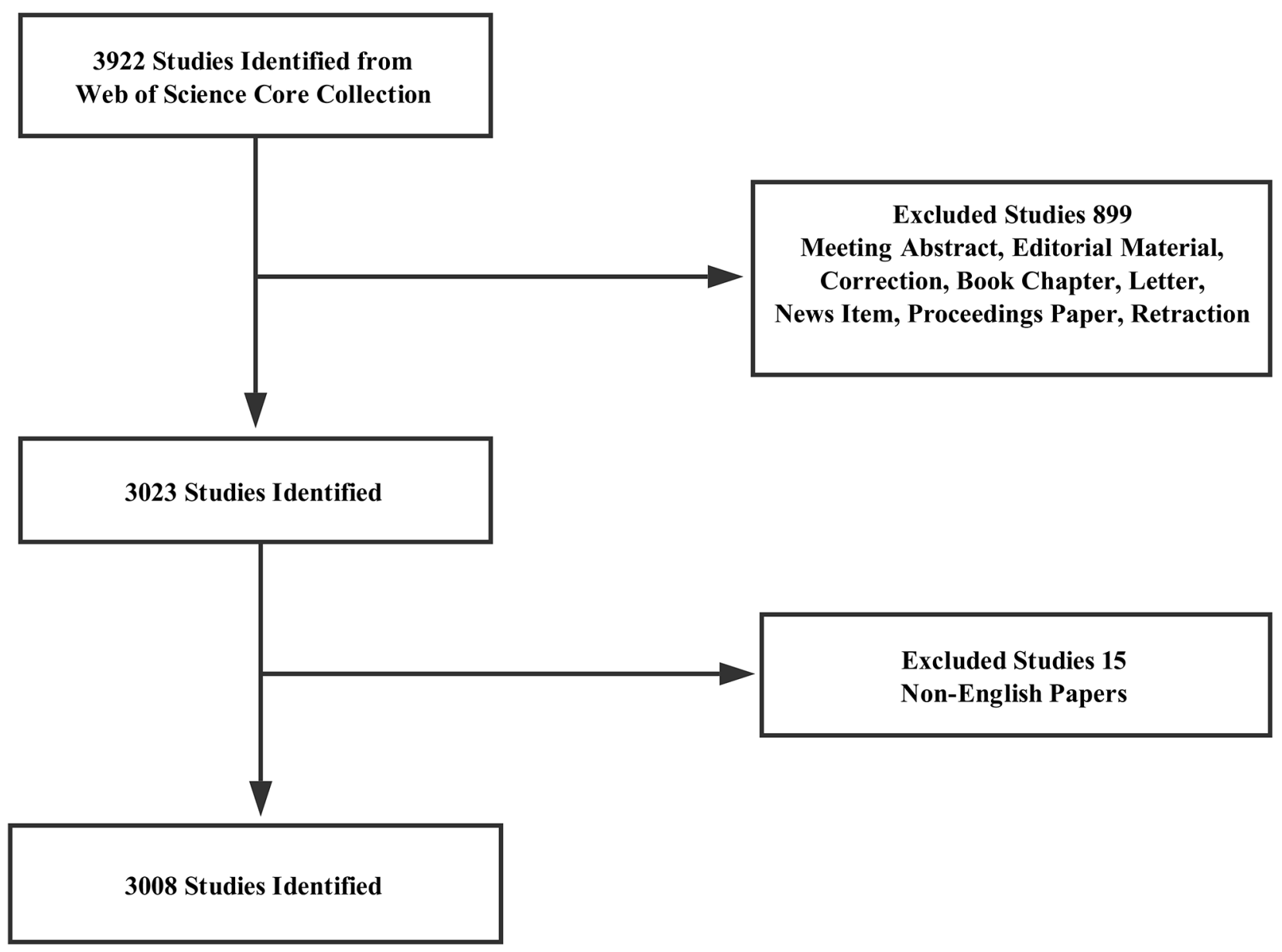

Figure 1: Flow chart of IncRNA studies inclusion. 
Table 1: The top 15 journals that published articles on IncRNA research

\begin{tabular}{|c|c|c|c|c|c|}
\hline Rank & Journal title & Country & Count & Percent & IF 2016 \\
\hline 1 & Oncotarget & United States & 203 & $6.75 \%$ & 5.168 \\
\hline 2 & Tumor Biology & Switzerland & 125 & $4.16 \%$ & 3.650 \\
\hline 3 & PLoS ONE & United States & 118 & $3.92 \%$ & 2.806 \\
\hline 4 & Scientific Reports & England & 97 & $3.23 \%$ & 4.259 \\
\hline 5 & $\begin{array}{c}\text { International } \\
\text { Journal of Clinical } \\
\text { and Experimental } \\
\text { Pathology }\end{array}$ & United States & 94 & $3.13 \%$ & 1.706 \\
\hline 6 & $\begin{array}{l}\text { Nucleic Acids } \\
\text { Research }\end{array}$ & England & 46 & $1.53 \%$ & 10.162 \\
\hline 7 & $\begin{array}{c}\text { Biochemical and } \\
\text { Biophysical Research } \\
\text { Communications }\end{array}$ & United States & 41 & $1.36 \%$ & 2.466 \\
\hline 8 & Oncology Reports & Greece & 38 & $1.26 \%$ & 2.662 \\
\hline 9 & $\begin{array}{l}\text { Molecular Medicine } \\
\text { Reports }\end{array}$ & Greece & 34 & $1.13 \%$ & 1.692 \\
\hline 10 & BMC Genomics & England & 33 & $1.10 \%$ & 3.729 \\
\hline 11 & $\begin{array}{l}\text { Biomed Research } \\
\text { International }\end{array}$ & United States & 33 & $1.10 \%$ & 2.476 \\
\hline 12 & Molecular Cell & United States & 32 & $1.06 \%$ & 14.714 \\
\hline 13 & $\begin{array}{c}\text { Biomedicine \& } \\
\text { Pharmacotherapy }\end{array}$ & France & 32 & $1.06 \%$ & 2.759 \\
\hline 14 & $\begin{array}{l}\text { International Journal } \\
\text { of Molecular Sciences }\end{array}$ & Switzerland & 31 & $1.03 \%$ & 3.226 \\
\hline 15 & Oncology Letters & Greece & 30 & $1.00 \%$ & 1.390 \\
\hline
\end{tabular}

Molecular Cell (IF2016, 14.714) had an impact factor (IF) greater than 10.000; 1 of the journals, including Oncotarget (IF2016, 5.168) had an IF between 5.000 and 10.000; 4 of the journals, including Tumor Biology (IF2016, 3.650), Scientific Reports (IF2016, 4.259), BMC Genomics (IF2016, 3,729), and International Journal of Molecular Sciences (IF2016, 3.226) had an IF between 3.000 and 5.000. Moreover, the journals with high IF (greater than 3.000 ) contributed to $18.86 \%$ (IF $>10.000$, $2.59 \% ; 10.000>\mathrm{IF}>5.000,6.75 \% ; 5.000>\mathrm{IF}>3.000$, $9.52 \%$ ) of the total number of publications. In summary, it was challenging of publishing papers related to lncRNA research in high-IF journals.

In the list of top 10 countries (5 European countries, 2 American countries, and 3 Asia-Pacific countries), China was the only developing country, contributed to more than $60 \%$ of the total number of publications, indicating that it has made significant progress in this field. Although China had a huge advantage in the number of publications, the United States showed its dominant position in both citation frequency and $\mathrm{H}$-index. Therefore, from the perspective of research quality, the United States was the leading country in this field. Regarding the collaboration network, there was a broad range of cooperation between Western nations. The strongest collaborations were identified among the United States, Australia, and Italy, between France and Sweden, and between Spain and Singapore.

In the list of top 10 institutions, except Harvard University, the remaining 9 institutions were all from China. Moreover, Chinese institutions accounted for the largest proportion in the collaboration network. That is the reason why China contributed to the most number of publications related to lncRNA research.

\section{Citation data}

According to the top 10 authors identified in this analysis, each contributed to no fewer than 35 papers. Therefore, they were identified as "prolific authors." However, none of these prolific authors were included in the list of top 10 co-cited authors, with regard to annual co-citation counts, suggesting that prolific 
authors should consider more about their quality of papers while working to increase their number of papers. For co-cited authors, the authors who had at least 1,000 co-citation counts, include Guttman M, who provided an emerging model that identified modular regulatory principles of lncRNAs [16]; Mercer TR, who reported the structure and function of
lncRNAs in epigenetic regulation [17]; and Rinn JL, who explored the genome regulation by lncRNAs [18]. Although none of these authors belonged to prolific authors, they made crucial contributions to lncRNA research.

For co-cited references, the map of co-citation clusters in the timeline view indicated that the most

A
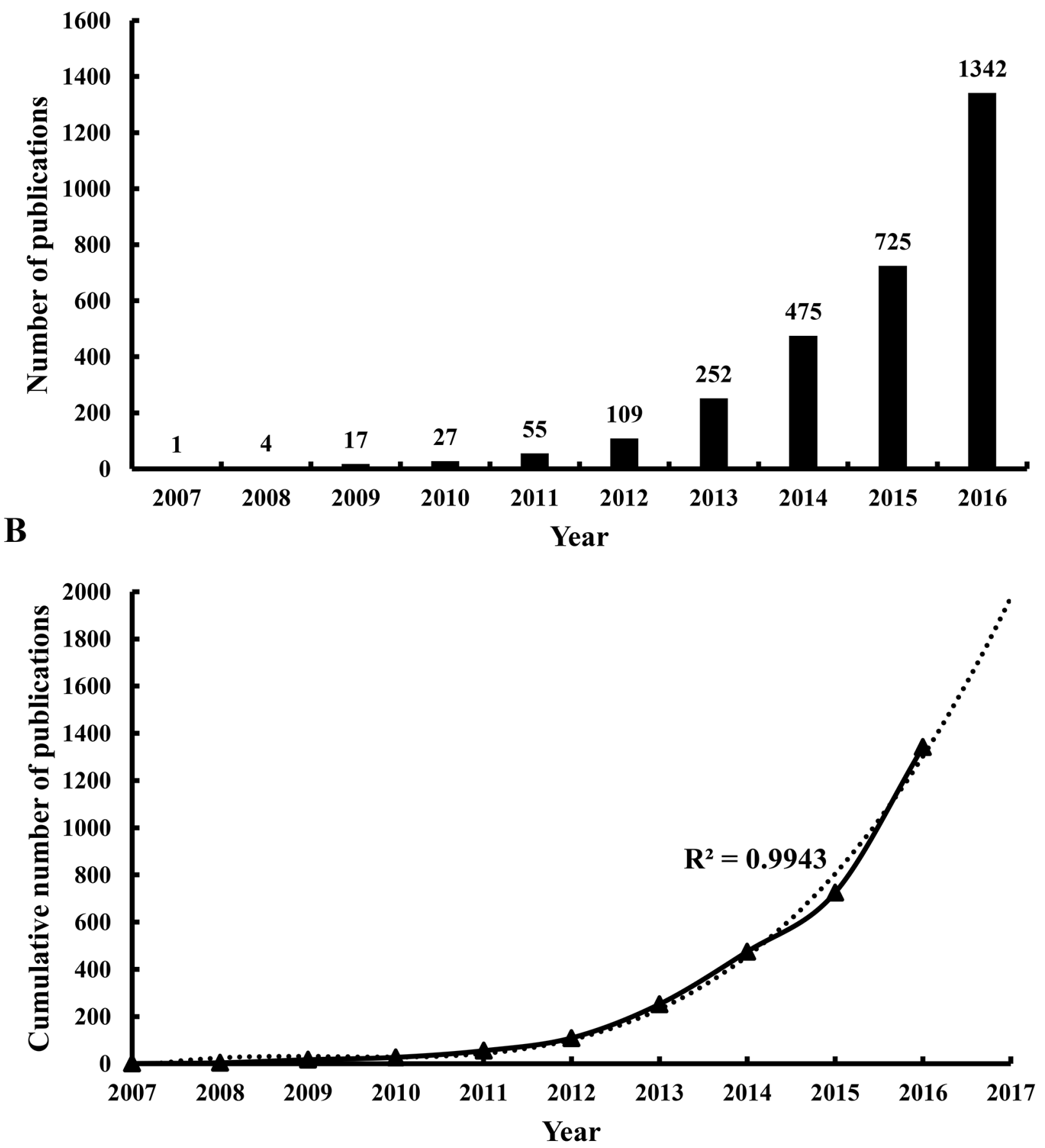

Figure 2: Publication outputs and growth prediction. (A) The number of annual publications on lncRNA research from 2007 to 2016; (B) The model fitting curve of growth trend of lncRNA publications. 
Table 2: The top 10 countries and institutions contributed to publications on IncRNA research

\begin{tabular}{lcccc}
\hline Rank & Country & Count & Institution & Count \\
\hline 1 & China & 1843 & Nanjing Medical University & 225 \\
2 & United States & 779 & Shanghai Jiao Tong & 125 \\
& University & \\
3 & Germany & 108 & Chinese Academy of & 102 \\
4 & Sciences & 89 \\
5 & England & 100 & Harbin Medical University & 80 \\
6 & Japan & 97 & Fudan University & 78 \\
7 & Australia & 78 & Harvard University & 75 \\
8 & Italy & Sun Yat-Sen University & 63 \\
9 & Spain & 57 & Second Military Medical & 61 \\
10 & France & 51 & Shandong University & 60 \\
\hline
\end{tabular}

influential references were concentrated in the period from 2009 to 2012. The top 10 co-cited references were shown in Table 3, and they were regarded as the intellectual bases in IncRNA research. Gupta RA (2010), who published in Nature, had the highest co-citation counts (930), followed by Derrien T (2012, 543 co-citation counts), Tsai MC (2010, 535 co-citation counts), and Guttman M (2009, 477 co-citation counts), who published in Genome Research, Science, and Nature respectively. Furthermore, Genes \& Development, Molecular Cell, Annual Review of Biochemistry, Nature Review Genetics, and Proceedings of the National Academy of Sciences also published some highly influential papers. These journals were fundamental in this field.

\section{Research frontiers}

Keywords with bursts (abrupt changes or emerging trends) provide a reasonable prediction of research frontiers [19]. In this instance, CiteSpace IV was used to capture the keywords with the strongest citation bursts that identified as research frontiers over time. The time intervals were plotted on the blue line, while the periods of burst keywords were plotted on the red line, indicating the beginning and end of the time interval of each burst

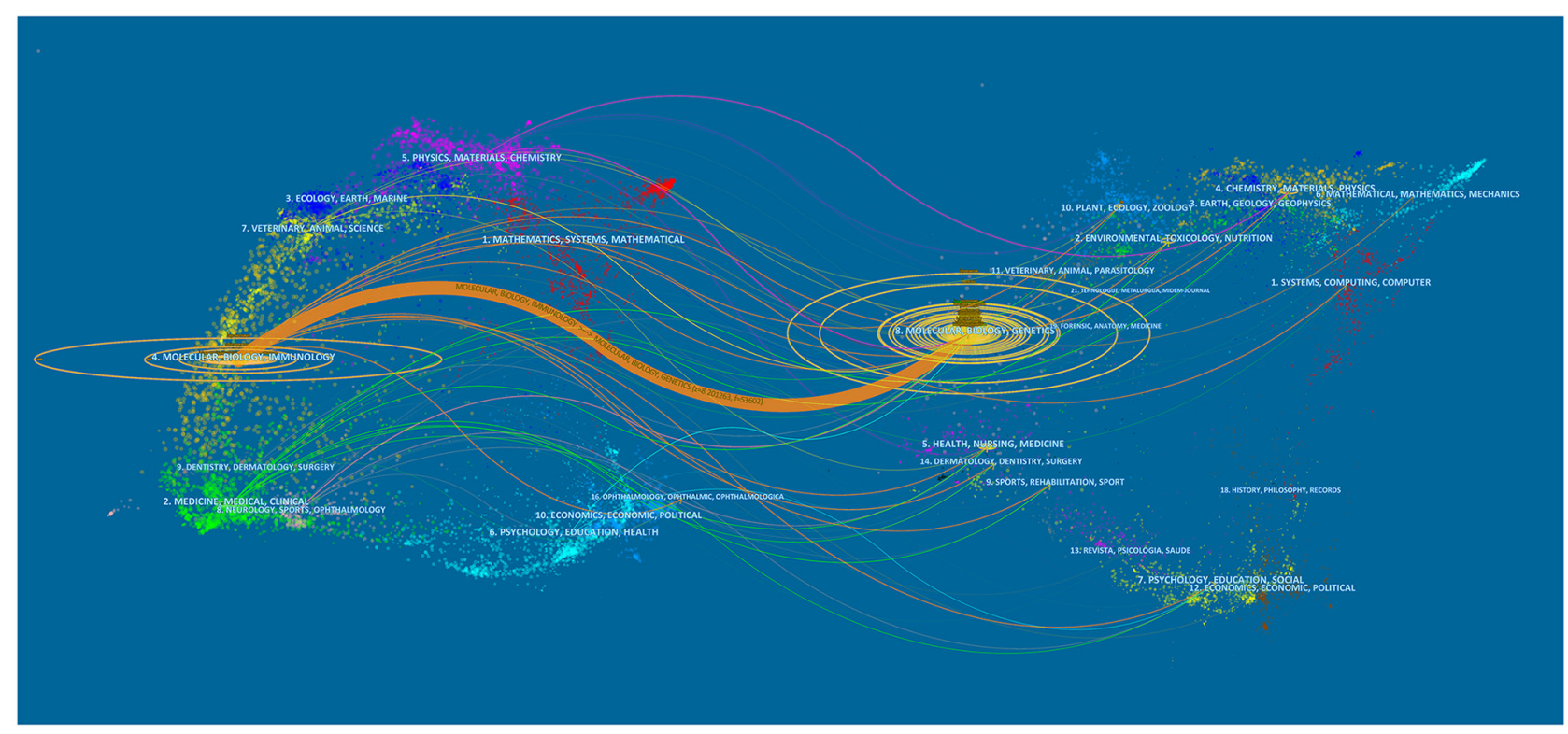

Figure 3: The dual-map overlay of journals related to IncRNA research. 
A
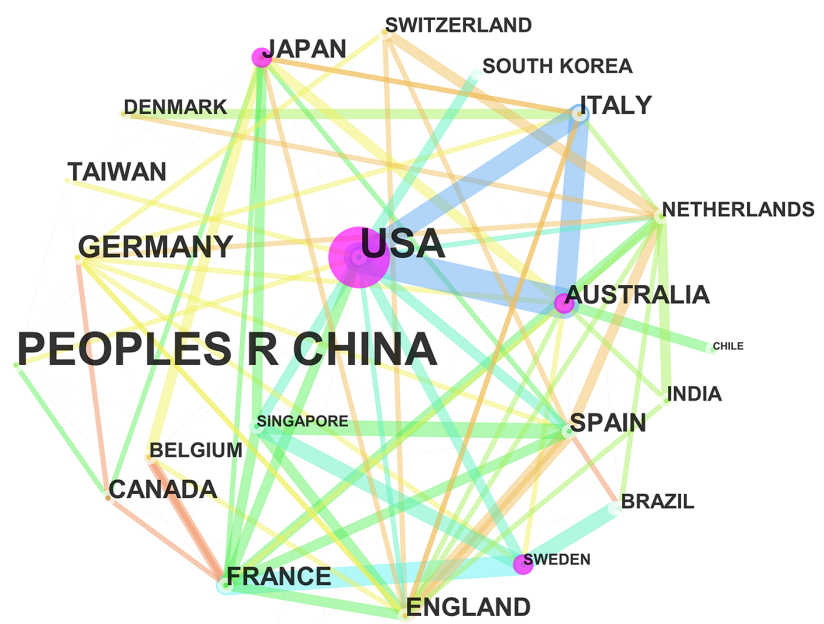

B

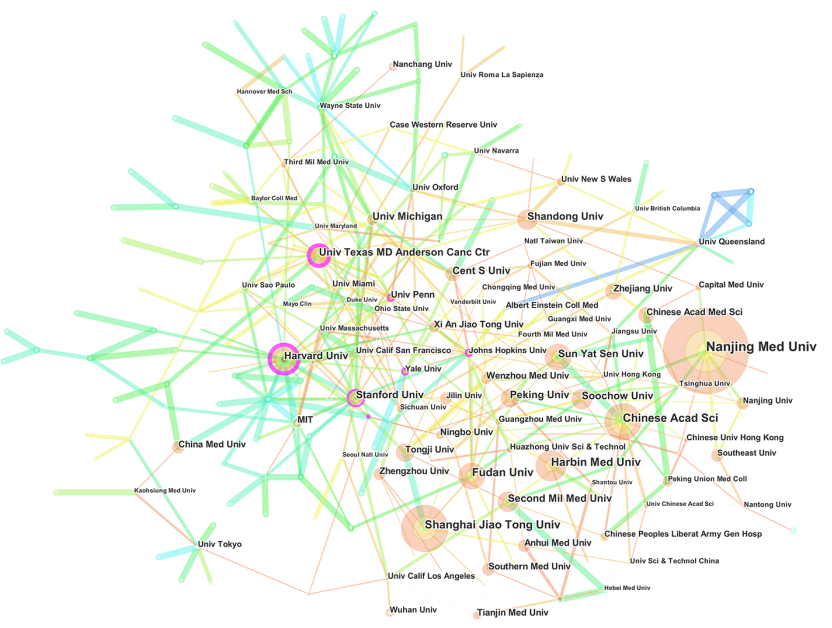

Figure 4: The analysis of countries and institutions. (A) Network map of countries/territories engaged in lncRNA research; (B) Network map of institutions engaged in lncRNA research.

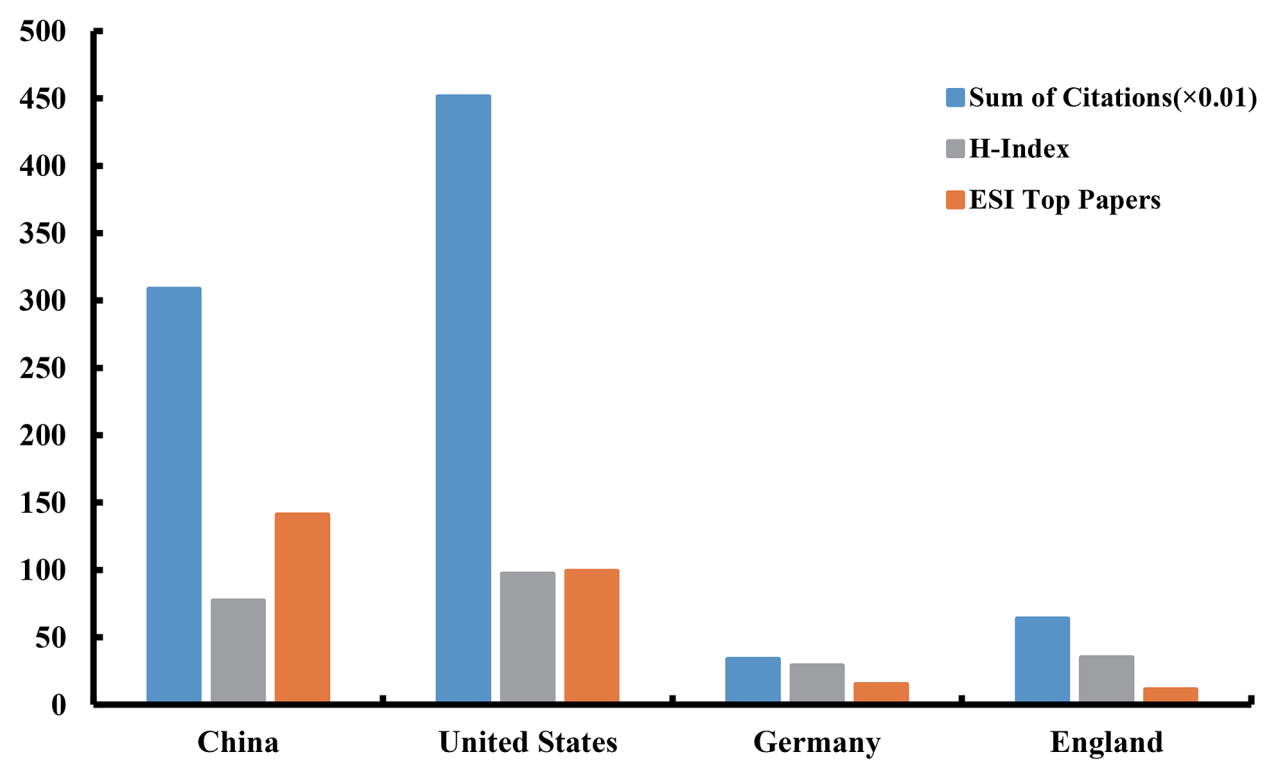

Figure 5: The citation counts $(\times 0.01), \mathrm{H}$-index, and ESI top papers in the top four countries. 
A
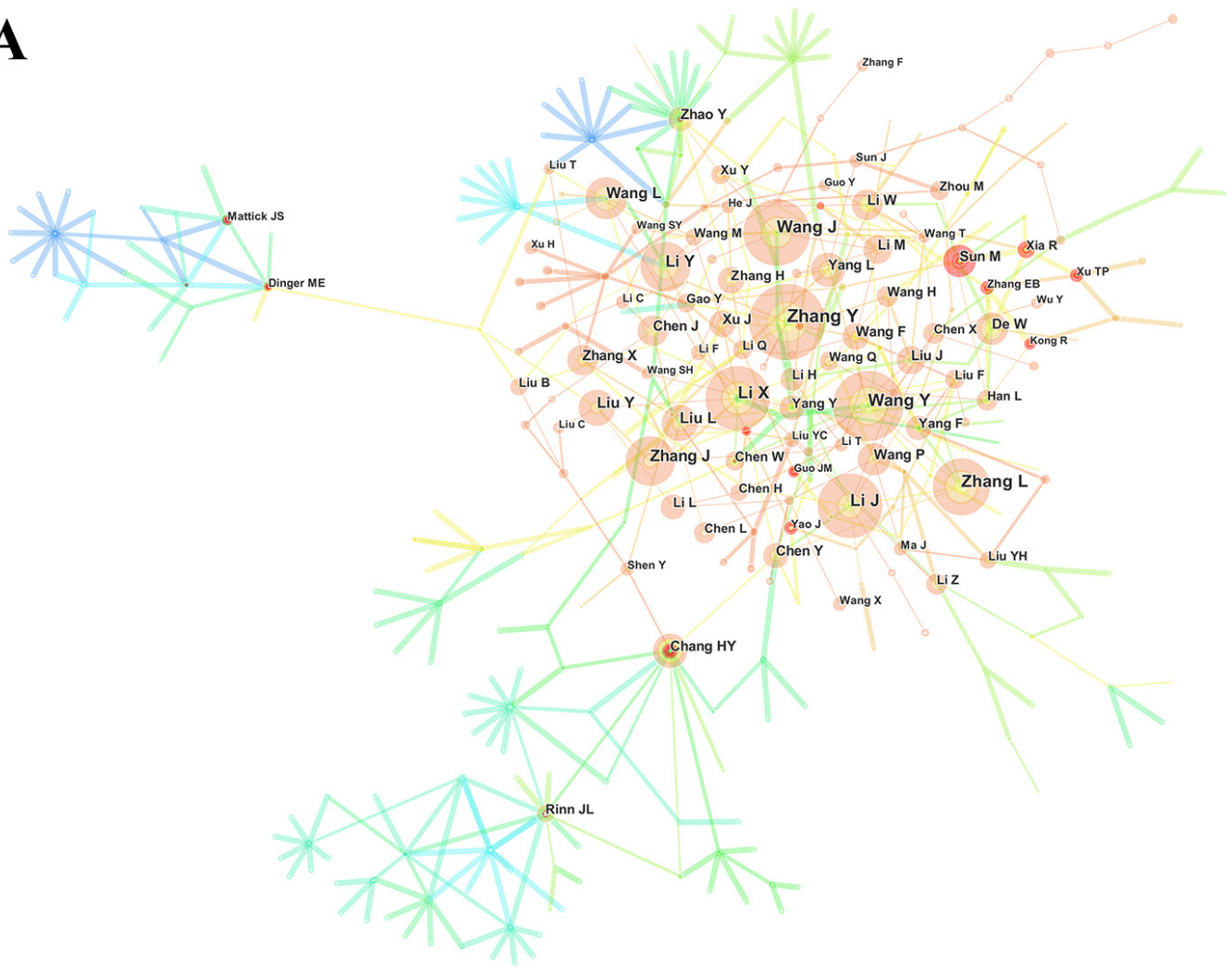

B

Figure 6: The analysis of authors. (A) Network map of active authors contributed to lncRNA research; (B) Network map of co-cited authors contributed to lncRNA research. 
Table 3: The top 10 authors, co-cited authors, and co-cited references in IncRNA research

\begin{tabular}{|c|c|c|c|c|c|c|}
\hline Rank & Author & Count & Co-cited Author & Count & Co-cited Reference & Count \\
\hline 1 & Zhang Y & 72 & Guttman M & 1556 & $\begin{array}{c}\text { Gupta RA, 2010, Nature, } \\
\text { V464, P1071 }\end{array}$ & 930 \\
\hline 2 & Wang Y & 67 & Mercer TR & 1213 & $\begin{array}{l}\text { Derrien T, 2012, Genome } \\
\text { Research, V22, P1775 }\end{array}$ & 543 \\
\hline 3 & Wang J & 63 & Rinn JL & 1147 & $\begin{array}{c}\text { Tsai MC, 2010, Science, } \\
\text { V329, P689 }\end{array}$ & 535 \\
\hline 4 & $\mathrm{Li} \mathrm{J}$ & 60 & Gupta RA & 932 & $\begin{array}{c}\text { Guttman M, 2009, Nature, } \\
\text { V458, P223 }\end{array}$ & 477 \\
\hline 5 & Li X & 58 & Wang KC & 753 & $\begin{array}{l}\text { Cabili MN, 2011, Genes \& } \\
\text { Development, V25, P1915 }\end{array}$ & 461 \\
\hline 6 & Zhang L & 56 & Ponting CP & 708 & $\begin{array}{c}\text { Wang KC, 2011, Molecular } \\
\text { Cell, V43, P904 }\end{array}$ & 450 \\
\hline 7 & Zhang J & 49 & Tsai MC & 701 & $\begin{array}{c}\text { Rinn JL, 2012, Annual } \\
\text { Review of Biochemistry, } \\
\text { V81, P145 }\end{array}$ & 427 \\
\hline 8 & Li Y & 47 & Prensner JR & 683 & $\begin{array}{c}\text { Mercer TR, 2009, Nature } \\
\text { Review Genetics, V10, P155 }\end{array}$ & 423 \\
\hline 9 & Wang L & 41 & Gutschner T & 652 & $\begin{array}{l}\text { Huarte M, 2010, Cell, V142, } \\
\text { P409 }\end{array}$ & 422 \\
\hline 10 & Liu Y & 37 & Khalil AM & 622 & $\begin{array}{c}\text { Khalil AM, 2009, } \\
\text { Proceedings of the National } \\
\text { Academy of Sciences, V106, } \\
\text { P11667 }\end{array}$ & 409 \\
\hline
\end{tabular}

[20]. The top four research frontiers of lncRNA research were listed as follows:

i. Database: Many bioinformatics studies on lncRNAs have been conducted in recent years. The lncRNA profiles in these studies were mainly obtained from two databases: The Cancer Genome Atlas (TCGA) database and Gene Expression Omnibus (GEO) database. The lncRNA sequence extracted from TCGA or GEO were analyzed via bioinformatics methods, and lncRNAexpression signatures were identified as potential prognostic biomarkers for related cancer [21-24]. Moreover, the association between lncRNA expression and epigenetic regulation can also be revealed through bioinformatics analysis [25-27]. Apart from the two databases mentioned above, there are some specialized databases for lncRNA, including PLncDB [28], lncRNASNP [29], LncReg [30], and LNCCipedia [31], and so forth. These databases provide comprehensive data for IncRNA bioinformatics research.

ii. Meta-analysis: Many of the meta-analysis papers related to lncRNA research have been published in recent years, including some that were high-quality [32-34].

iii. Xist RNA: Xist RNA is a long noncoding RNA, which orchestrates $\mathrm{X}$ chromosome inactivation, a process that entails chromosome silencing and remodeling the three-dimensional structure of the $\mathrm{X}$ chromosome [35]. However, this argument remains controversial. A recent study found that Xist-mediated silencing required a direct interaction between Xist RNA and Lamin B receptor (an integral part of the nuclear lamina) [36]. The results indicated that Xist-mediated silencing needs lamina recruitment [36]. Apart from this, some studies have focused on the role and molecular mechanisms of Xist RNA in disease progression [37-39].

iv. Genome-wide association study: The genomewide association study (GWAS) is an examination, where whole-gene variants in different individuals were examined, to evaluate the association of any variant with a trait [40]. GWAS involves the association between single-nucleotide polymorphisms (SNPs) and traits such as major human diseases [41]. In lncRNA research, GWAS has been used to reveal the different patterns of epigenetic features in lncRNA loci [42] and to identify susceptible lncRNAs as a disease-related risk factor [43-46].

\section{Strengths and limitations}

Data on lncRNA publications were retrieved and collected from Web of Science Core Collection (WoSCC) database (Science Citation Index-Expanded journals). 
The analysis of data was relatively comprehensive and objective. However, the most of the publications in the WoSCC database were in English. Publication in non-English were very few. Other databases (e.g. Ovid, PubMed, Scopus, and Google Scholar) were not analyzed since WoSCC is more advanced at providing detailed data (e.g. annual publications, journal sources, author information, country and institution information). Secondly, the results of bibliometric analysis and the results of actual research conditions were still different, as some recent publications do not have a high citation count. Lastly, although all searches were retrieved on June 17, 2017, to avoid bias due to the update of WoSCC database for the year 2016, the database is still receiving new data.
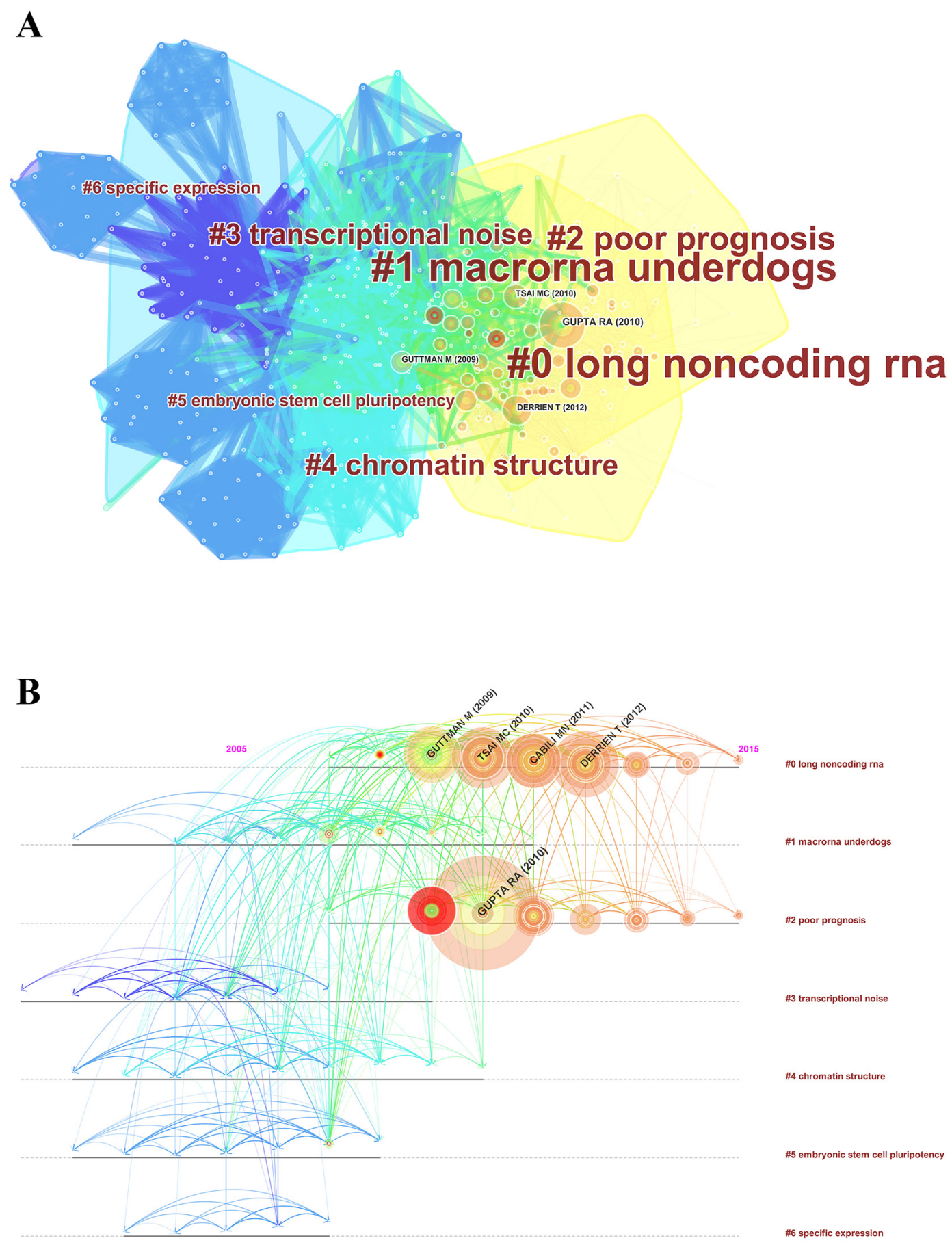

Figure 7: The analysis of references. (A) Co-citation map of references from publications on lncRNA research; (B) Co-citation map (timeline view) of references from publications on lncRNA research. 
Despite this, we think this paper includes the vast majority of publications from 2016, and the small amount of new data may not change the conclusion.

\section{CONCLUSION}

This study helps investigators master the trends of lncRNA research. The top three journals that contributed to the largest number of publications were Oncotarget, Tumor Biology, and PLoS ONE. China, United States, and Germany were the top three countries engaged in lncRNA research. The strongest cooperation was observed between developed countries, particularly, the United States was in the dominant position. There were many Chinese institutions engaged in lncRNA research, but significant collaborations among them were not noticed. Guttman M

\begin{tabular}{|c|c|c|c|c|c|}
\hline Keywords & Year & Strength & Begin & End & $2007-2016$ \\
\hline transcription & 2007 & 13.3131 & 2007 & 2013 & $=$ \\
\hline identification & 2007 & 10.0551 & 2007 & 2012 & $=$ \\
\hline noncoding rna & 2007 & 7.6002 & 2009 & 2013 & $=$ \\
\hline antisense rna & 2007 & 13.2388 & 2009 & 2014 & $=$ \\
\hline small nucleolar rna & 2007 & 2.4847 & 2009 & 2012 & $=$ \\
\hline mouse & 2007 & 10.356 & 2009 & 2013 & $=-$ \\
\hline repressive histone methylation & 2007 & 3.1061 & 2009 & 2012 & $=$ \\
\hline kenq1ot1 & 2007 & 2.4847 & 2009 & 2012 & $=$ \\
\hline xist gene & 2007 & 5.9493 & 2009 & 2013 & $=$ \\
\hline human cell & 2007 & 14.4102 & 2009 & 2014 & $=$ \\
\hline sequence & 2007 & 7.1031 & 2009 & 2014 & $=$ \\
\hline messenger rna & 2007 & 12.4016 & 2009 & 2013 & 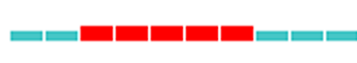 \\
\hline beckwith wiedemann syndrome & 2007 & 3.7276 & 2009 & 2012 & $=$ \\
\hline map & 2007 & 2.7228 & 2009 & 2010 & $=$ \\
\hline heat shock & 2007 & 3.9807 & 2009 & 2011 & $=$ \\
\hline chromatin & 2007 & 24.8607 & 2009 & 2014 & 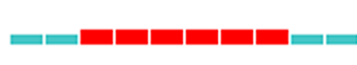 \\
\hline$x$ chromosome inactivation & 2007 & 21.8409 & 2009 & 2014 & $=$ \\
\hline polymerase ii & 2007 & 10.2824 & 2009 & 2013 & $==$ \\
\hline genome & 2007 & 16.3828 & 2009 & 2013 & 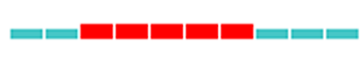 \\
\hline dosage compensation & 2007 & 5.6372 & 2010 & 2012 & 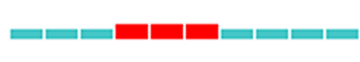 \\
\hline in vivo & 2007 & 16.7854 & 2010 & 2014 & 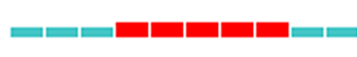 \\
\hline genome wide association & 2007 & 11.2877 & 2010 & 2016 & 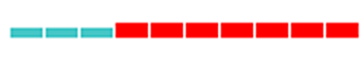 \\
\hline xist rna & 2007 & 7.0322 & 2012 & 2016 & 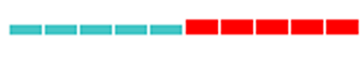 \\
\hline meta analysis & 2007 & 35.3129 & 2014 & 2016 & 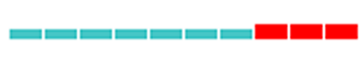 \\
\hline database & 2007 & 11.9261 & 2014 & 2016 & (घ)=ோ \\
\hline
\end{tabular}

Figure 8: The keywords with the strongest citation bursts of publications on IncRNA research. 
(Broad Institute, United States), Mercer TR (University of Queensland, Australia), Rinn JL (Harvard University, United States), and Gupta RA (Stanford University, United States) may be good candidates for research collaboration in this field. "Database," "Xist RNA," and "Genome-wide association study" may be the latest research frontiers, and related studies may pioneer this field in the next few years.

\section{MATERIALS AND METHODS}

\section{Source of the data and search strategy}

Literature was searched from the Science Citation Index-Expanded (SCI-E) of the Web of Science Core Collection (WoSCC) of Clarivate Analytics on June 17, 2017. The data were extracted from the public database. Ethical approval was not applicable in this case.

The following terms were used: $\mathrm{TI}=$ ("IncRNA*") $\mathrm{TI}=$ ("Inc RNA*") OR TI= ("long ncRNA*") OR TI= ("long non translated RNA*") OR TI= ("long non coding RNA*") OR TI= ("long non protein coding RNA*") OR $\mathrm{TI}=$ ("long noncoding RNA*") $\mathrm{OR} \mathrm{TI}=$ ("long untranslated RNA*") OR $\mathrm{TI}=$ ("long intergenic non protein coding RNA*") OR TI= ("large intergenic non coding RNA*") OR TI= ("large intergenic noncoding RNA*") OR TI= ("lincRNA*") OR TI= ("linc RNA*") AND Language $=$ English. In this case, only articles and reviews were included.

\section{Data collection}

All data were independently collected by two authors (Yan Miao and Si-Yi Xu) and downloaded in TXT format. The data were imported into CiteSpace IV (Drexel University, Philadelphia, United States) and Microsoft Excel 2016 (Redmond, Washington, United States), and qualitatively and quantitatively analyzed.

\section{Statistical methods}

WoSCC analyzed the characteristics of publications, including annual publications, journal sources, countries or territories, institutions, authors, citation counts, ESI top papers, and $\mathrm{H}$-index.

Microsoft Excel 2016 was used to analyze the time trend of publications. The model: $f(x)=a x^{3}+b x^{2}+c x$ $+d$ was used to predict future trend of papers in this field, based on the cumulative number of publications. Symbol $x$ represented the publication year, and $f(x)$ was the cumulative number of publications by the year.

CiteSpace IV was used to (i) capture the relationship between citing journals and cited journals, (ii) identify the collaborations between countries/institutions/authors, (iii) perform co-citation analysis on authors and references, (iv) perform a citation-burst analysis of keywords, and (v) generate visualizations of all the items mentioned above.

\section{Abbreviations}

lncRNA: long noncoding RNA; WoSCC: Web of Science Core Collection; SCI-E: Science Citation Index-Expanded; IF: impact factor; TCGA: The Cancer Genome Atlas; GEO: Gene Expression Omnibus; GWAS: Genome-wide association study; SNPs: single-nucleotide polymorphisms.

\section{Author contributions}

Study conception and design: Yan Miao; Data acquisition: Yan Miao, Si-Yi Xu; Data analysis and interpretation: Yan Miao, Si-Yi Xu, Lu-Si Chen; Manuscript preparation: Yan Miao; Final approval of manuscript: Yan Miao, Si-Yi Xu, Lu-Si Chen, Ge-Yu Liang, Yue-Pu Pu, Li-Hong Yin.

\section{ACKNOWLEDGMENTS}

This study was supported by the National Natural Science Foundation of China (No. 81573191). We thank Prof. Bei Wang for her help in the statistical analyses.

\section{CONFLICTS OF INTEREST}

The authors declare no financial interests in the findings described in this study.

\section{REFERENCES}

1. Perkel JM. Visiting "noncodarnia". Biotechniques. 2013; 54: 301, 3-4. https://doi.org/10.2144/000114037.

2. Morris KV, Mattick JS. The rise of regulatory RNA. Nature reviews Genetics. 2014; 15: 423-37. https://doi.org/10.1038/ nrg3722.

3. Mattick JS, Rinn JL. Discovery and annotation of long noncoding RNAs. Nat Struct Mol Biol. 2015; 22: 5-7. https://doi.org/10.1038/nsmb.2942.

4. Lee JT. Epigenetic Regulation by Long Noncoding RNAs. Science. 2012; 338: 1435-9. https://doi.org/10.1126/ science. 1231776 .

5. Zhao W, Luo J, Jiao S. Comprehensive characterization of cancer subtype associated long non-coding RNAs and their clinical implications. Sci Rep. 2014; 4: 6591. https://doi. org/10.1038/srep06591.

6. Fatica A, Bozzoni I. Long non-coding RNAs: new players in cell differentiation and development. Nat Rev Genet. 2014; 15: 7-21. https://doi.org/10.1038/nrg3606.

7. Lu Q, Ren S, Lu M, Zhang Y, Zhu D, Zhang X, Li T. Computational prediction of associations between long noncoding RNAs and proteins. BMC Genomics. 2013; 14: 651. https://doi.org/10.1186/1471-2164-14-651.

8. Ouyang J, Zhu X, Chen Y, Wei H, Chen Q, Chi X, Qi B, Zhang L, Zhao Y, Gao George F, Wang G, Chen JL. 
NRAV, a long noncoding RNA, modulates antiviral responses through suppression of interferon-stimulated gene transcription. Cell Host \& Microbe. 2014; 16: 616-26. https://doi.org/10.1016/j.chom.2014.10.001.

9. Cajigas I, Leib DE, Cochrane J, Luo H, Swyter KR, Chen S, Clark BS, Thompson J, Yates JR, Kingston RE, Kohtz JD. Evf2 lncRNA/BRG1/DLX1 interactions reveal RNA-dependent inhibition of chromatin remodeling. Development. 2015; 142: 2641-52. https://doi.org/10.1242/ dev. 126318 .

10. Zhao XY, Lin JD. Long noncoding RNAs: a new regulatory code in metabolic control. Trends in Biochemical Sciences. 2015; 40: 586-96. http://dx.doi.org/10.1016/j. tibs.2015.08.002.

11. Gutschner T, Hammerle M, Eissmann M, Hsu J, Kim Y, Hung G, Revenko A, Arun G, Stentrup M, Gross M, Zornig M, MacLeod AR, Spector DL, et al. The noncoding RNA MALAT1 is a critical regulator of the metastasis phenotype of lung cancer cells. Cancer Res. 2013; 73: 1180-9. https:// doi.org/10.1158/0008-5472.can-12-2850.

12. Wang Y, He L, Du Y, Zhu P, Huang G, Luo J, Yan X, Ye B, Li C, Xia P, Zhang G, Tian Y, Chen R, et al. The long noncoding RNA lncTCF7 promotes self-renewal of human liver cancer stem cells through activation of Wnt signaling. Cell Stem Cell. 2015; 16: 413-25. https://doi.org/10.1016/j. stem.2015.03.003.

13. Ling H, Spizzo R, Atlasi Y, Nicoloso M, Shimizu M, Redis RS, Nishida N, Gafa R, Song J, Guo Z, Ivan C, Barbarotto E, De Vries I, et al. CCAT2, a novel noncoding RNA mapping to $8 \mathrm{q} 24$, underlies metastatic progression and chromosomal instability in colon cancer. Genome Res. 2013; 23: 1446-61. https://doi.org/10.1101/gr.152942.112.

14. Augoff K, McCue B, Plow EF, Sossey-Alaoui K. miR31 and its host gene lncRNA LOC554202 are regulated by promoter hypermethylation in triple-negative breast cancer. Molecular Cancer. 2012; 11: 5. https://doi. org/10.1186/1476-4598-11-5.

15. Van Raan AF. The use of bibliometric analysis in research performance assessment and monitoring of interdisciplinary scientific developments. Technology Assessment-Theory and Practice. 2003; 1: 20-9.

16. Guttman M, Rinn JL. Modular regulatory principles of large non-coding RNAs. Nature. 2012; 482: 339-46. https://doi. org/10.1038/nature10887.

17. Mercer TR, Mattick JS. Structure and function of long noncoding RNAs in epigenetic regulation. Nat Struct Mol Biol. 2013; 20: 300-7. https://doi.org/10.1038/ nsmb. 2480 .

18. Rinn JL, Chang HY. Genome regulation by long noncoding RNAs. Annu Rev Biochem. 2012; 81: 145-66. https://doi. org/10.1146/annurev-biochem-051410-092902.

19. Chen C. CiteSpace II: Detecting and visualizing emerging trends and transient patterns in scientific literature. Journal of the American Society for Information Science and
Technology. 2006; 57: 359-77. https://doi.org/10.1002/ asi.20317.

20. Zhou X, Zhao G. Global liposome research in the period of 1995-2014: a bibliometric analysis. Scientometrics. 2015; 105: 231-48. https://doi.org/10.1007/s11192-015-1659-6.

21. Zhong L, Lou G, Zhou X, Qin Y, Liu L, Jiang W. A sixlong non-coding RNAs signature as a potential prognostic marker for survival prediction of ER-positive breast cancer patients. Oncotarget. 2017; 8: 67861-67870. https://doi. org/10.18632/oncotarget.18919.

22. Zhan X, Dong C, Liu G, Li Y, Liu L. Panel of seven long noncoding RNA as a candidate prognostic biomarker for ovarian cancer. Onco Targets Ther. 2017; 10: 2805-13. https://doi.org/10.2147/ott.s128797.

23. Zhou M, Zhang Z, Zhao H, Bao S, Cheng L, Sun J. An immune-related six-lncRNA signature to improve prognosis prediction of glioblastoma multiforme. Mol Neurobiol. 2017. https://doi.org/10.1007/s12035-017-0572-9.

24. Wang P, Ning S, Zhang Y, Li R, Ye J, Zhao Z, Zhi H, Wang T, Guo Z, Li X. Identification of IncRNA-associated competing triplets reveals global patterns and prognostic markers for cancer. Nucleic Acids Res. 2015; 43: 3478-89. https://doi.org/10.1093/nar/gkv233.

25. Wu SC, Kallin EM, Zhang Y. Role of H3K27 methylation in the regulation of IncRNA expression. Cell research. 2010; 20: 1109-16. https://doi.org/10.1038/cr.2010.114.

26. Paralkar VR, Taborda CC, Huang P, Yao Y, Kossenkov AV, Prasad R, Luan J, Davies JO, Hughes JR, Hardison RC, Blobel GA, Weiss MJ. Unlinking an lncRNA from Its Associated cis Element. Molecular Cell. 2016; 62: 104-10. https://doi.org/10.1016/j.molcel.2016.02.029.

27. Liao Q, He W, Liu J, Cen Y, Luo L, Yu C, Li Y, Chen $\mathrm{S}$, Duan S. Identification and functional annotation of lncRNA genes with hypermethylation in colorectal cancer. Gene. 2015; 572: 259-65. https://doi.org/10.1016/j. gene.2015.07.028.

28. Jin J, Liu J, Wang H, Wong L, Chua NH. PLncDB: plant long non-coding RNA database. Bioinformatics. 2013; 29: 1068-71. https://doi.org/10.1093/bioinformatics/btt107.

29. Gong J, Liu W, Zhang J, Miao X, Guo AY. IncRNASNP: a database of SNPs in lncRNAs and their potential functions in human and mouse. Nucleic Acids Research. 2015; 43: D181-D6. https://doi.org/10.1093/nar/gku1000.

30. Zhou Z, Shen Y, Khan MR, Li A. LncReg: a reference resource for lncRNA-associated regulatory networks. Database. 2015; 2015: bav083-bav. https://doi.org/10.1093/ database/bav083.

31. Volders PJ, Verheggen K, Menschaert G, Vandepoele K, Martens L, Vandesompele J, Mestdagh P. An update on LNCipedia: a database for annotated human lncRNA sequences. Nucleic Acids Research. 2015; 43: D174-D80. https://doi.org/10.1093/nar/gku1060.

32. Serghiou S, Kyriakopoulou A, Ioannidis JPA. Long noncoding RNAs as novel predictors of survival in 
human cancer: a systematic review and meta-analysis. Molecular Cancer. 2016; 15. https://doi.org/10.1186/ s12943-016-0535-1.

33. Hong HH, Hou LK, Pan X, Wu CY, Huang H, Li B, Nie W. Long non-coding RNA UCA1 is a predictive biomarker of cancer. Oncotarget. 2016; 7: 44442-7. https://doi. org/10.18632/oncotarget.10142.

34. Zhang S, Chen S, Yang G, Gu F, Li M, Zhong B, Hu J, Hoffman A, Chen M. Long noncoding RNA HOTAIR as an independent prognostic marker in cancer: A Meta-Analysis. PLos One. 2014; 9: e105538. https://doi.org/10.1371/ journal.pone.0105538.

35. Engreitz JM, Pandya-Jones A, McDonel P, Shishkin A, Sirokman K, Surka C, Kadri S, Xing J, Goren A, Lander ES, Plath K, Guttman M. The Xist lncRNA Exploits ThreeDimensional Genome Architecture to Spread Across the X Chromosome. Science. 2013; 341. https://doi.org/10.1126/ science. 1237973 .

36. Chen CK, Blanco M, Jackson C, Aznauryan E, Ollikainen N, Surka C, Chow A, Cerase A, McDonel P, Guttman M. $\mathrm{X}$ ist recruits the $\mathrm{X}$ chromosome to the nuclear lamina to enable chromosome-wide silencing. Science. 2016; 354: 468-72. https://doi.org/10.1126/science.aae0047.

37. Wang H, Shen Q, Zhang X, Yang C, Cui S, Sun Y, Wang L, Fan X, Xu S. The long non-coding RNA XIST controls non-small cell lung cancer proliferation and invasion by modulating miR-186-5p. Cell Physiol Biochem. 2017; 41: 2221-9. https://doi.org/10.1159/000475637.

38. Echevarria L, Benistan K, Toussaint A, Dubourg O, Hagege AA, Eladari D, Jabbour F, Beldjord C, De Mazancourt P, Germain DP. X-chromosome inactivation in female patients with Fabry disease. Clin Genet. 2016; 89: 44-54. https://doi. org/10.1111/cge.12613.

39. Gu S, Xie R, Liu X, Shou J, Gu W, Che X. Long coding RNA XIST contributes to neuronal apoptosis through the downregulation of AKT phosphorylation and is negatively regulated by miR-494 in rat spinal cord injury. Int J Mol Sci. 2017; 18. https://doi.org/10.3390/ijms18040732.

40. Chung CC, Chanock SJ. Current status of genome-wide association studies in cancer. Hum Genet. 2011; 130: 59-78. https://doi.org/10.1007/s00439-011-1030-9.

41. Marchini J, Howie B. Genotype imputation for genomewide association studies. Nat Rev Genet. 2010; 11: 499-511. https://doi.org/10.1038/nrg2796.

42. Sati S, Ghosh S, Jain V, Scaria V, Sengupta S. Genome-wide analysis reveals distinct patterns of epigenetic features in long non-coding RNA loci. Nucleic Acids Research. 2012; 40: 10018-31. https://doi.org/10.1093/nar/gks776.

43. Fava VM, Manry J, Cobat A, Orlova M, Van Thuc N, Moraes MO, Sales-Marques C, Stefani MM, Latini AC, Belone AF, Thai VH, Abel L, Alcais A, et al. A genome wide association study identifies a lncRna as risk factor for pathological inflammatory responses in leprosy. PLoS Genet. 2017; 13: e1006637. https://doi.org/10.1371/journal. pgen. 1006637.

44. Awata T, Yamashita H, Kurihara S, Morita-Ohkubo T, Miyashita Y, Katayama S, Mori K, Yoneya S, Kohda M, Okazaki Y, Maruyama T, Shimada A, Yasuda K, et al. A genome-wide association study for diabetic retinopathy in a japanese population: potential association with a long intergenic non-coding RNA. PLOS ONE. 2014; 9: e111715. https://doi.org/10.1371/journal.pone.0111715.

45. Gao P, Wei GH. Genomic Insight into the Role of lncRNA in Cancer Susceptibility. Int J Mol Sci. 2017; 18. https://doi. org/10.3390/ijms18061239.

46. Ballantyne RL, Zhang X, Nunez S, Xue C, Zhao W, Reed E, Salaheen D, Foulkes AS, Li M, Reilly MP. Genome-wide interrogation reveals hundreds of long intergenic noncoding RNAs that associate with cardiometabolic traits. Hum Mol Genet. 2016; 25: 3125-41. https://doi.org/10.1093/hmg/ ddw154. 